\title{
Analysis and Forecast of Construction Waste Based on ARIMA Model
}

\author{
Song Zhaoxiang ${ }^{1}$ Li Yan $^{1,2}$ Huang Zhirong ${ }^{1}$ \\ (1, College of Civil Engineering and Architecture, Hainan University, Hainan Haikou 570228, China \\ 2. School of Management and Economics, Tianjin University, Tianjin 300072, China, \\ Institute of International Tourism Island, Hainan University, Hainan Haikou 570228, China)
}

Keywords: urban construction waste; output estimation and prediction; ARIMA forecast model

Abstract: In the construction waste output forecast, it is difficult for forecasting and reducing the accuracy of forecasting. In this paper, a method for estimating the yield of urban construction waste is built on the basis of building area, by using the ARIMA model to predict demolition area and the area of the building was completed, from the empirical coefficient method and indirect method to predict for construction waste production. Haikou as an example to calculate and predict the 2015-2020 years of urban cons truction waste output.

\section{Overvie w of related forecasting methods for construction waste}

In recent years, with the accelerated pace of urban construction, construction waste will be generated with a large number of production. According to the source of construction waste and the way of producing, construction waste can be divided into three categories, in the construction site of construction waste, public buildings and residential decorative decoration construction waste and housing demolition ${ }^{[1]}$.

The muck from construction sites can basically reach the balance of supply and demand. The processed resources mainly for decoration waste, demolition waste and garbage remaining under construction. At present, the prediction model of construction waste generated mainly includes Multiple Regression Model, Grey Model and Time Series Prediction. Multiple Regression Model is used to combine the urban population, urban residents' income, and then to predict the future construction waste output ${ }^{[2]}$. Grey system processing is using a certain mathematical method to eliminate the influence which based on the analysis of the observed data the establishment of the system can make a prediction of the Gray Model ${ }^{[3]}$. Through the process of forecasting target's own time series to study the forecast target itself on the change trends, so the prediction of the future of the data is a Time Series Model Prediction method ${ }^{[4]}$.

These existing estimation method, however, there are factors to consider not to comprehensive, the data quantity demand is high or relatively poor commonality problem and so forth. Therefore, it is necessary to build a set of general method for the estimation of urban construction waste output based on the existing conditions. The ARIMA model based on time series analysis method in this paper, introducing the difference parameters $d$, in order to solve the data loss caused by the imbalance in non-stationary time series.

\section{ARIMA model calculus ideas}

Determination of prediction methods should be flexible to choose according to actual situation. Through the investigation of the current situation of construction waste in Haikou, we know that there is no statistical data about the construction and decoration waste in Haikou. Analyzing the 
statistical data of the direct relationship of the amount of construction waste contain the construction of the demolition areas and the decoration areas ${ }^{[5]}$. The use of the general construction's industry of the demolition and renovation of the unit area of construction waste generated, combined with the quantitative forecast future demolition, decoration area of construction waste production amount. That is:

$$
S=\sum_{i=1}^{n=3} S_{i}
$$

$$
S_{i}=X_{i} \eta_{i}
$$

Where $S$ is the amount of construction waste generated, $S_{i}$ is for the classification of construction waste, $X_{i}$ for the corresponding garbage construction area, $\eta_{i}$ is the corresponding coefficient of garbage classification (Set decoration area $=$ then existing housing construction area $\times 10 \%)^{[6]}$.

The prediction model used in this research is ARIMA model, which is a relatively mature model, suitable for short-term forecasting and only for stationary time series. The process can produce some kind of a stable new time series, further improvements $\operatorname{ARIMA}(p, q)$ model, using the model $\operatorname{ARIMA}(p, q, d)$ model ${ }^{[7]} . d$ is the number of the original time difference series when the non-stationary time series converted into stationary time series. Using $\operatorname{ARMA}(p, q, d)$ model fits the data in the process, in essence, is the first observational data differencing $d$ times, and then fitting $\operatorname{ARIMA}(p, q)$ model.

$\operatorname{ARIMA}(p, q, d)$ mathematical form as follows:

$$
\Phi_{1}(B) \nabla^{d} X_{t}=\theta(B) \varepsilon_{t}
$$

Where: $\mathrm{t}$ represents Time, $X_{i}$ represents Response Sequence; $B$ is the Backward Shift operator; $\mathrm{V}=1-\mathrm{B} ; p, d, q$, respectively, Regression order, Difference order and Moving Average order; $\Phi_{1}(B)$ represents Auto Regressive operator; $\theta(B)$ represents Sliding Average operator. In this paper, data processing and analyzing to fit ARIMA $(p, q, d)$ through the SPSS 22.0 software

\section{Results Analysis}

\section{Haikou city construction completion and de molition of the status quo}

According to the definition of demolition waste, demolition area is the direct cause of rise in demolition of garbage output, but the decoration waste production is completed based on building process, and the amount of decoration of waste is closely related to the area of existing building area. Haikou construction completed residential area of the time series from 2006 to 2014 is shown in Table 1.

\begin{tabular}{ccccccccccc}
\multicolumn{1}{c}{ Table 1 } & \multicolumn{1}{c}{ Completed Residential Area In HaiKou } & $\mathrm{m}^{2}$ \\
\hline Time & $\mathbf{2 0 0 6}$ & 2007 & 2008 & 2009 & 2010 & 2011 & 2012 & 2013 & 2014 \\
\hline $\begin{array}{c}\text { Complet } \\
\text { ed }\end{array}$ & $\mathbf{8 0 2 2 0}$ & $\mathbf{1 3 0 0 1}$ & $\mathbf{1 1 3 6 6}$ & $\mathbf{1 1 7 8 0}$ & $\mathbf{1 2 8 8 4}$ & $\mathbf{3 3 1 7 4}$ & $\mathbf{3 0 7 4 1}$ & $\mathbf{1 9 5 0 0}$ & $\mathbf{3 9 3 6 6}$ \\
$\begin{array}{c}\text { residenti } \\
\text { al areas }\end{array}$ & 8 & 93 & 65 & 98 & 80 & 3 & 68 & 92 & 35 \\
\hline
\end{tabular}

Due to the lack of historical data in the area of the demolition of Haikou city, this study Haikou 
city demolition area data acquisition refer to big city for completion of construction waste generation characteristics of the ratio of completion area and demolition area ${ }^{[8]}$. So we can estimate the Haikou demolition area number of historical and forecast data under demolition area and completion area coefficients.

\section{Prediction of construction completion and demolition area of Haikou city Data preparation process}

This research adopts the SPSS 22.0 to analyze the data of the construction completion area of Haikou in 2006-2014, from the data of Table 1, it can be seen that Haikou construction completion area has not significantly increased or decreased trend, does not require a smooth processing of the data. So, $d=0$

\section{Determination of coefficients for model}

In order to find the best order, using the ACF, PACF figure and Akaike Information Criterion minimum (AIC), Schwarz-Bayes criterion (BIC) a combination of methods to determine the optimal order of the model ${ }^{[9]}$. According autocorrelation and partial autocorrelation (see Figure 1) can be seen, are expressed as tailing phenomenon for ARMA model, ARIMA(3,0,3) model initially selected.
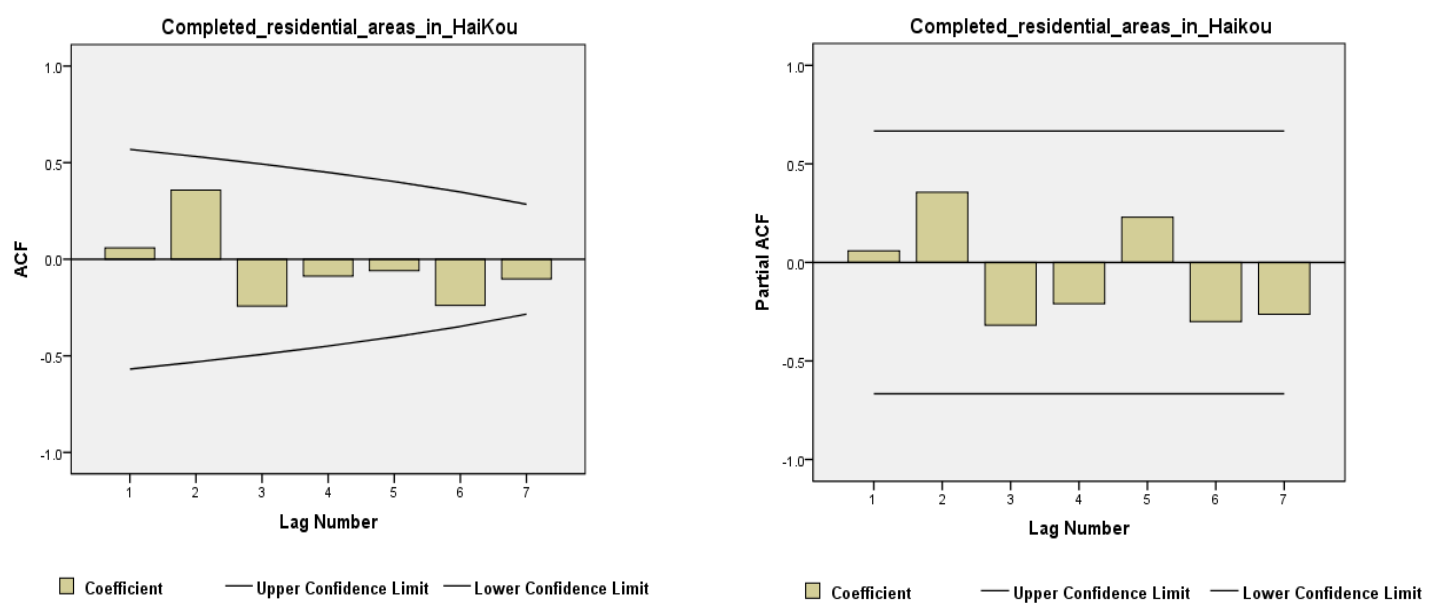

Figure 1 Completed residential areas sequence autocorrelation and partial autocorrelation

\section{Suitability test sequence}

Adaptability test of model is the sequence of the original data and the fitting error of the data sequence (residual sequence) corresponding test, see whether it is consistent with the actual situation, whether it can reflect the objective situation very well. We used the ACF and PACF diagrams of the residual series to test the white noise sequence. ACF diagrams and PACF diagrams of the residual sequence are shown in Figure 2. Figure 2 shows: the residual sequence is white noise sequences, therefore, the model ARIMA $(3,0,3)$ can be a good fit to the time series of Haikou city completed construction area.

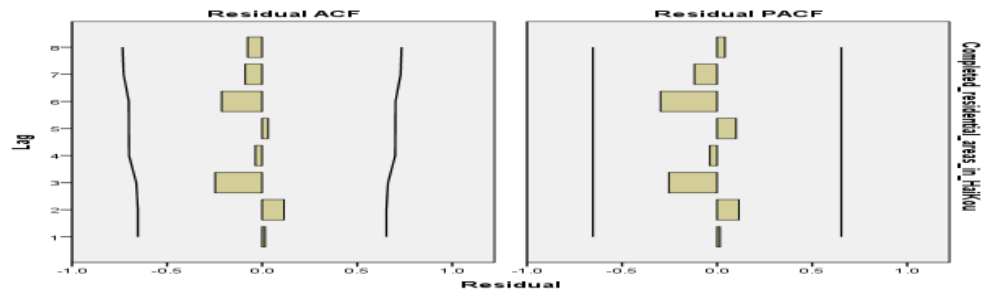

Figure 2 residuals' autocorrelation and partial autocorrelation 


\section{Construction completion a rea forecast}

With ARMA $(3,0,3)$ model to predict Haikou City construction completion area, thus the model predictions 2015--2020 Haikou City building completed in the area are shown in Table 2, 2006--2020 Haikou City construction completion area time series shown in Figure 3.

Referring to the characteristics of the large city construction waste generation with construction completed area and the demolition of the area of the coefficient (about 0.61) to estimate the demolition of the area of the time series of Haikou City shown in Table 3.

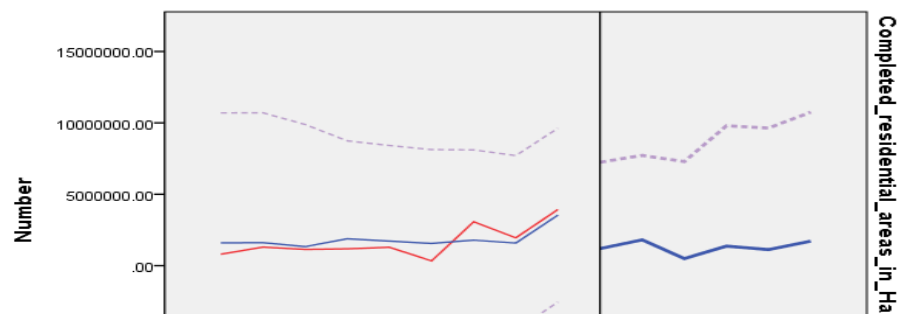

Figure 3 Completed residential areas' time sequence in HaiKou

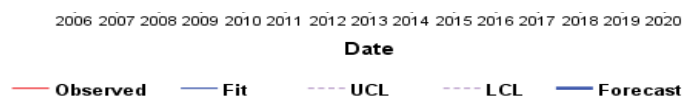

Table 2 Forecast Completed Residential Areas In HaiKou

\begin{tabular}{|c|c|c|c|c|c|c|c|}
\hline \multicolumn{2}{|c|}{ Model } & 2015 & 2016 & 2017 & 2018 & 2019 & 2020 \\
\hline & Foreca & 1195354.9 & 1807847.0 & & 1366776.0 & 1123854.8 & 1716941.8 \\
\hline Complete & st & 4 & 7 & & 7 & 3 & 2 \\
\hline & & 7242649.3 & 7723893.7 & 7290324.8 & 9797226.1 & 9638634.9 & 10749400 . \\
\hline residenti & UCL & 4 & 0 & 1 & 3 & 2 & 63 \\
\hline al areas & LCL & $\begin{array}{c}-4851939 . \\
46\end{array}$ & $\begin{array}{c}-4108199 . \\
55\end{array}$ & $\begin{array}{c}-6303525 . \\
85\end{array}$ & $\begin{array}{c}-7063673 . \\
99\end{array}$ & $\begin{array}{c}-7390925 . \\
25\end{array}$ & $\begin{array}{l}-7315516.9 \\
8\end{array}$ \\
\hline
\end{tabular}

\section{Construction waste production forecast}

According to the actual situation of the Haikou and statistics, the demolition areas forecast 2006-2014 demolition areas in Haikou as the basis. It is the existing housing construction areas in Haikou that the decoration areas can be project according to certain cycle as a basis. Combining with the construction budget law, with reference to the construction industry related information of this study is to take removal coefficient of $1.05 \mathrm{t} / \mathrm{m}^{2}$ (demolition of construction waste production amount per unit area), under construction in the rest of the construction waste coefficient of 0.15 $\mathrm{t} / \mathrm{m}^{2}$. Decorate coefficient is $0.1 \mathrm{t} / \mathrm{m}^{2}$ (decorate garbage output per unit area) ${ }^{[10]}$. The generated coefficient calculation of construction waste production is shown in table 3 according to the different types of construction waste. 
Table 3 Construction waste production In HaiKou

\begin{tabular}{ccccccc}
\hline Time & 2015 & 2016 & 2017 & 2018 & 2019 & 2020 \\
\hline $\begin{array}{c}\text { decoration } \\
\text { waste }\end{array}$ & 239.13 & 324.26 & 92.64 & 264.86 & 218.93 & 302.62 \\
$\begin{array}{c}\text { New } \\
\text { residual } \\
\text { waste }\end{array}$ & 179.31 & 271.18 & 74.09 & 205.02 & 168.58 & 257.54 \\
$\begin{array}{c}\text { demolition } \\
\text { waste }\end{array}$ & 1212.62 & 1631.64 & 972.31 & 1037.22 & 689.84 & 874.33 \\
total & 1631.06 & 2227.08 & 1139.04 & 1507.1 & 1077.35 & 1434.49 \\
\hline
\end{tabular}

\section{The model prediction results}

It can be seen from table 3 that the Haikou construction waste is mainly composed of demolition waste, accounting for more than $70 \%$ of the total construction waste produced, followed by decorate garbage, its production accounted for about $15 \%$ of the total construction waste, discharge the least is under construction in the rest of the trash, less than $10 \%$ of the total construction waste. Seeing from the characteristics of all kinds of construction waste, under construction in the rest of the construction waste, components is relatively single and pollution is small. Demolition waste is relatively fixed and the larger output category mainly contains concrete and broken block. Decorate buildings have mixed composition of construction waste, hazardous substances. So the management should be increased the demolition waste and the recycling of the waste harmless and decorate management efforts for construction waste.

\section{Reference:}

[1]. Wang Ruimin, Wang Linxiu. The current situation of construction waste analysis and development prospects [J]. China Urban Economy, 2011, 05:178-179.

[2]. Sang Jin. Based on the multiple regression model of planning implementation evaluation method research [J]. Planner, 2013, 10:79-85.

[3]. Bao Han, Liu Suiqing. Application of grey model to predict in the water supply pipe network leakage [J]. Water Supply and drainage, 2010, 01:157-159.

[4]. Howell Tong, Threshold models in time series analysis-Some reflections [J].Journal of Econometrics, December 2015, Pages 485-491

[5]. Gao Qingsong, Lei Qiongchang, He Hua, Construction waste recycling ind ustry in China the causes and countermeasures of development slow [J]. Ecological economy, 2012, $12: 128-131+135$.

[6]. Wang Guiqin, Zhang Hongyu, Li Guoxue, The application of the grey model in Beijing building garbage output prediction field in environmental engineering [J].2009, 27 (S1) 508-511

[7]. Xu Liping, Luo Mingzhi. Based on the analysis of ARIMA model gold price short-term predictions [J]. Finance Economics, 2011 01: 26-34. 
[8]. Zhao Jun, Liu Qiuxia, Lin Liqing, Qian Guangren, Qiao Jianzhuang. Big city construction waste generation characteristics of evolution and comparison [J]. Journal of central south university (natural science edition), 2013 03: 1297-1304..

[9]. V.A. Morozov, N.V. Morozova, V.B. Zlokazov, Implementation of autocorrelation method for investigations of the scintillator decay time and space correlation of radiation [J].Nuclear Instruments and Methods in Physics Research.1 March 2015, Pages 148-153

[10]. Zhou Wenjuan, Chen Jialong, Lu Hongbo. Construction waste resource utilization present situation in our country and the countermeasures [J]. Architectural Technology,2009,08:741-744 